\title{
Process of Building an Educational and a Military Ontology for the Mexican Context
}

\author{
Cristal Karina Galindo Durán ${ }^{1}$, R. Carolina Medina-Ramírez ${ }^{1}$, \\ María Auxilio Medina Nieto ${ }^{2}$, José Luis García-Cué ${ }^{3}$ \\ ${ }^{1}$ Universidad Autónoma Metropolitana - Iztapalapa, Departmento de Ingeniería Eléctrica, \\ Mexico City, Mexico \\ ${ }^{2}$ Universidad Politécnica de Puebla, Departamento de Posgrado, Puebla, Mexico \\ ${ }^{3}$ Colegio de Postgraduados, Campus Montecillo, Texcoco, State of Mexico, Mexico \\ cdgalindod@gmail.com, cmed@xanum.uam.mx \\ maria.medina@uppuebla.edu.mx, jlgcue@colpos.mx
}

\begin{abstract}
This article presents a process to build ontologies for the educational and military domains focused on the representation of knowledge in Mexican institutions. The Mexican context is represented by the structure of these institutions, their teaching modalities and considering the educational strategies to enable students to achieve good cognitive and formative levels. The ontologies are used by individuals of the Military Education System as training tools. The article includes the description of some tests for ontology evaluation. The preliminary results show that these tools are acceptable for potential users.
\end{abstract}

Keywords: knowledge model, ontology, education, military.

\section{Introduction}

The Semantic Web is an extension of the current web, which has a structure that enables to express the content of pages or documents so that computers can understand and process them, this fact facilitates interaction between computers and users [1]. To make this possible, we need knowledge models (ontologies), descriptions of resources; as well as management languages and knowledge representation techniques.

In particular, ontologies can have different purposes, among which stand out: the publication of information according to a knowledge model, the exchange of information between applications, the disambiguation of concepts, the inference of knowledge and the description of vocabularies $[2,3]$.

In recent years, multiple ontologies have emerged in different fields of knowledge ranging from Physics to Social Sciences [4]; however, the adaptation of ontologies in particular domains is a common task due to the need of covering specific domains, that means that although reutilization is recommendable, often only general concepts are maintained.

This article presents the construction of two ontologies: an educational and a military ontology focused on the representation of knowledge in Mexican institutions. The Mexican context is represented by the structure of these institutions, their teaching 
modalities and considering the educational strategies to enable students to achieve good cognitive and formative levels. These ontologies are used by individuals of the Military Education System as training tools, they are also part of the MIIDAS prototype, which is a proposal for the integration of educational resources managed through semantic technologies [5].

The rest of the article is structured as follows: Section II presents some concepts about ontologies. Section III presents a review of the ontologies developed in the educational and military domain. Section IV explains the process of building both ontologies. Section V shows preliminary results of ontologies' evaluation. Finally, conclusions and future work are presented in Section VI.

\section{Theoretical and Explanatory Framework}

The theoretical perspective of this work involves the topic of ontologies, which we describe below.

Ontologies can be conceived as an explicit and formal specification of a shared conceptualization [14]. From this definition, it can be said that the specification refers to the selection of a particular domain, the explicit refers to the concepts used in the ontology and the restrictions for its use that must be clearly defined, the formal describes the use of comprehensible syntax for computers, the conceptualization points to the representation of knowledge and shared refers to the consensus by domain experts [15].

According to [16], the main elements of ontology are: class (concepts), properties (relationships), and individuals (instances). Classes are real-world objects, which can be grouped with elements that have similar characteristics; these classes are the base element of ontology and describe the concepts of a specific domain. The properties are relationships and serve to describe relevant features of the entities; these can be of three types: object, data or annotation. Individuals are elements which belong to a specific class.

OWL (Ontology Web Language) is the standard language of the Semantic Web to express and codify ontologies [17], this language is based on descriptive logics. OWL language is composed of three sublanguages with different levels of expressivity, these are: 1) OWL-Lite for those cases that need a hierarchical classification and simple restrictions, 2) OWL-DL for those cases that require great expressiveness and a computability guaranteed and 3) OWL-Full for those cases that require maximum expressiveness and complete syntactic freedom; but without guarantee of complete computability. OWL also uses special software modules, called reasoners, that can make inferences and to check logic consistency into the knowledge base of ontologies.

\section{Related Work}

In this section, we present some ontologies that have been developed for the educational and military domains, the purpose is to review the concepts that can be adopted by our own ontologies for knowledge reuse. 
An ontology that represents a knowledge model which establishes the relationships between the requirements of the labor markets and the content of the work plans is presented in [6], the ontology is studied during a given training program. In the article [7] describes domain and pedagogical ontologies which together help to enable the search, visualization and navigation of learning objects in Science of the Earth and Geography areas. Curriculum Ontology [8] is an ontology proposed by the UK public radio and television service, which aims to provide data models and vocabularies to describe national curricula in the same country.

In the HERO ontology (Higher Education Reference Ontology) [9] several general aspects of the domain of a university are described, such as the organizational structure, personal (academic and administrative), roles (teaching and research) and even incomings.

Regarding ontologies in the military domain, the following stand out: the C2 ontology [10], this exposes a knowledge model that specifies military command and control concepts of the Department of Defense of the United States.

The military ontology Muninn [11] defines classes and properties of military history. The article [12] describes the implementation of an ontology as a basis for the intelligent information system of the tactical command of the army of Korea. The THOR ontology [13] provides a vocabulary to describe and request the content generated by the combatant.

As summary, the related works shows diverse ontologies from different perspectives, however, they do not consider the features of the Mexican context. That represents the organization of educational institutions in Mexico, their educational approaches, the teaching modalities and strategies used to achieve cognitive and formative levels of individuals of the Mexican Military Education System.

\section{$4 \quad$ Building Ontologies}

For the building of the ontologies Methodology 101 [18] was used, proposed by Stanford University, which consists of 7 phases, these phases are: 1) Determine the domain and scope of the ontology, 2) Reuse existing ontologies, 3) List important terms for the ontology, 4) Define classes and their hierarchy, 5) Define the properties of the classes: slots, 6) Define the facets of the slots and 7) Create instances or individuals.

\subsection{Building Phases for the Educational and Military Ontology}

Before building the ontologies it is necessary to define the domain and the scope of these, in order to determine it, it is essential to ask the competency questions. Table 1 shows the different competency questions for each one of the ontologies.

Once the competency questions have been formulated, the scope of the ontologies can be established. Table 2 shows its respective scope.

After analyzing the scope of the ontologies it is necessary to list the important terms; as well as defining its hierarchy. For the educational ontology, we worked with experts in education and pedagogy that helped to obtain the significant terms. 
Cristal Karina Galindo Durán, R. Carolina Medina-Ramírez, María Auxilio Medina Nieto, et al.

Table 1. Competency questions for educational and military ontologies. (Source: own research).

\begin{tabular}{ll}
\hline Ontology & Competency questions \\
\hline \multirow{4}{*}{ Educational } & -What kind of educational approach do Universidad Autónoma \\
& Metropolitana, Unidad Iztapalapa (UAMI) and Escuela Militar de \\
& Ingenieros (EMI) use? \\
& - What are the didactic strategies established at the UAMI and the EMI? \\
& -What are teaching strategies are used to achieve cognitive and formative \\
& -What are the test instruments used by the EMI? \\
\hline \multirow{3}{*}{ Military } & -What is the Plan of Assistance to the Civil Population in Cases of \\
& Disaster (DN-III-E)? \\
& -What are the values promoted by the Military Education System? \\
& -What is the responsibility of a captain? \\
& -What is a duty in the military field?
\end{tabular}

Table 2. The scope of the educational and military ontologies. (Source: own research).

\begin{tabular}{ll}
\hline Ontology & Scope \\
\hline Educational & $\begin{array}{l}\text { The ontology should describe several aspects of Mexican educational } \\
\text { institutions, such as their structure, their teaching modalities, the educational } \\
\text { strategies to achieve a cognitive and formative level in the students; as well as } \\
\text { the evaluation instruments used. }\end{array}$ \\
\hline \multirow{3}{*}{ Military } & $\begin{array}{l}\text { The ontology should describe the terminology used in the different subjects for } \\
\text { the training of military personnel in the various curricula of the Military } \\
\text { Education System. }\end{array}$ \\
\hline
\end{tabular}

Regarding the Military domain ontology, the taxonomy of concepts and their definitions were obtained by reviewing documents that belong to the Military Educational System. Figure 1 shows the hierarchy of classes of both ontologies.

\begin{tabular}{|c|c|}
\hline \multicolumn{2}{|c|}{ Hierarchy classes } \\
\hline Educational ontology & Military ontology \\
\hline \begin{tabular}{|l|} 
Actividad \\
criterioEvaluacion \\
EA \\
EnfoqueEducativo \\
EstrategiaDidactica \\
IES \\
Tecnologico \\
Universidad \\
InstrumentoEvaluacion \\
EscalaEstimativa \\
ListaCotejo \\
Rubrica \\
Materia $\equiv$ UnidadAprendizaje \\
ModalidadConduccion \\
ModeloEA \\
NivelCognitivo \\
NivelFormativo \\
ProgramaEstudio \\
RecursoEducativo \\
Taxonomia \\
UnidadAprendizaje $\equiv$ Materia
\end{tabular} & $\begin{array}{l}\text { Tema } \\
\text { Adiestramiento_Militar_Docente } \\
\text { Armamento_Militar } \\
\text { Aspecto_Tactico_Adtva } \\
\text { Derechos_Humanos } \\
\text { Ejercicios_Militares } \\
\text { Guerra_Irregular } \\
\text { Habilidad_Combatiente } \\
\text { Historia_del_Arte_Militar } \\
\text { Historia_Militar_de_México } \\
\text { Legislacion_Militar } \\
\text { Mando_Militar_Liderazgo } \\
\text { Navegacion_Terrestre } \\
\text { Operaciones_en_Campaña } \\
\text { Orden_Cerrado_de_Infanteria } \\
\text { Proteccion_Civil } \\
\text { Trabajos_comunes } \\
\text { Ética_Militar }\end{array}$ \\
\hline
\end{tabular}

Fig. 1. Hierarchy classes of the educational and military ontology. (Source: own research). 
Table 3. Object properties of the educational ontology. (Source: own research).

\begin{tabular}{l|l|l|l|l|l|l|l}
\hline Property & $\mathrm{I}$ & $\mathrm{F}$ & $\mathrm{T}$ & $\mathrm{S}$ & $\mathrm{R}$ & Domain & Range \\
\hline tieneProgEstudio & $\mathrm{Y}$ & $\mathrm{N}$ & $\mathrm{N}$ & $\mathrm{N}$ & $\mathrm{N}$ & $\begin{array}{l}\text { Educational } \\
\text { institution } \\
\text { (EI) }\end{array}$ & $\begin{array}{l}\text { Degree } \\
\text { program }\end{array}$ \\
\hline perteneceA & $\mathrm{Y}$ & $\mathrm{N}$ & $\mathrm{N}$ & $\mathrm{N}$ & $\mathrm{N}$ & $\begin{array}{l}\text { Degree } \\
\text { program }\end{array}$ & EI \\
\hline tieneMateria & $\mathrm{N}$ & $\mathrm{N}$ & $\mathrm{N}$ & $\mathrm{N}$ & $\mathrm{N}$ & $\begin{array}{l}\text { Degree } \\
\text { program }\end{array}$ & Subject \\
\hline tieneEstiloAprendizaje & $\mathrm{Y}$ & $\mathrm{N}$ & $\mathrm{N}$ & $\mathrm{N}$ & $\mathrm{N}$ & $\begin{array}{l}\text { Learning } \\
\text { Style Model }\end{array}$ & Learning style \\
\hline perteneceAModelo & $\mathrm{Y}$ & $\mathrm{N}$ & $\mathrm{N}$ & $\mathrm{N}$ & $\mathrm{N}$ & $\begin{array}{l}\text { Learning style } \\
\text { Learning } \\
\text { Style Model }\end{array}$ \\
\hline estableceEstrategiaApre & $\mathrm{N}$ & $\mathrm{N}$ & $\mathrm{N}$ & $\mathrm{N}$ & $\mathrm{N}$ & EI & $\begin{array}{l}\text { Learning } \\
\text { strategy }\end{array}$ \\
\hline \multicolumn{7}{c}{$\begin{array}{l}\text { Symbology } \\
\text { I: Inverse F: Functional N: Transitive S: Symmetric R: Reflexive }\end{array}$} \\
\hline
\end{tabular}

In summary, the educational ontology has 22 classes, 15 object properties, 18 data properties and 22 annotations. The military ontology has 284 classes and their corresponding annotations. Protégé editor was used to build the ontologies; they are implemented in OWL version 2 language.

\section{Ontologies Evaluation}

The quality of the built ontologies was estimated by considering three aspects: structural evaluation, functional evaluation and usability. These aspects were tested as follows.

\subsection{Structural Evaluation}

The structural evaluation consists of analyzing the logical structure of the ontology. Three different reasoners were used to verify the logical consistency as well as the redundancy of information, they were FaCT ++ [19], Pellet [20] and HermiT [21], all of them reported no inconsistencies or redundancies in the educational and military ontologies.

\subsection{Functional Evaluation}

Functional evaluation refers to the use of ontology; as well as the conceptualization of some domain. This evaluation includes aspects such as the agreement of domain experts, evaluation through competency questions and an estimation of user satisfaction. 
Table 4. Competency questions for the educational and military ontology with its corresponding query in SPARQL and its result. (Source: own research).

\begin{tabular}{|c|c|c|c|}
\hline Ontology & $\begin{array}{l}\text { Natural language } \\
\text { query }\end{array}$ & Query in SPARQL & Result \\
\hline \multirow[t]{2}{*}{ Educational } & $\begin{array}{l}\text { Which educational } \\
\text { institution does the } \\
\text { Bachelor of } \\
\text { Computer Science } \\
\text { belong to? }\end{array}$ & $\begin{array}{l}\text { PREFIX oed: } \\
\text { <http://pcyti.izt.uam.mx/pmiidas/ontoeduca\#> } \\
\text { SELECT ?ies WHERE \{ } \\
\text { ?PEstudio oed:perteneceA ?ies } \\
\text { FILTER regex (?PEstudio, "^Licenciatura en } \\
\text { Computación")\} }\end{array}$ & UAMI \\
\hline & $\begin{array}{l}\text { How many } \\
\text { teaching strategies } \\
\text { does EMI establish } \\
\text { for teaching } \\
\text { practice? }\end{array}$ & $\begin{array}{l}\text { SELECT (count (?Estrategia) as } \\
\text { ?numEstrategia) WHERE \{ } \\
\text { ?uni oed:estableceEstrategia ?Estrategia } \\
\text { FILTER regex (?uni, " ^EMI ") \} }\end{array}$ & 5 \\
\hline \multirow[t]{2}{*}{ Military } & $\begin{array}{l}\text { What is the duty of } \\
\text { a captain? }\end{array}$ & $\begin{array}{l}\text { PREFIX po: } \\
\text { <http://pcyti.izt.uam.mx/pmiidas/ontomilitar\#> } \\
\text { PREFIX rdfs: } \\
\text { <http://www.w3.org/2000/01/rdf-schema\#> } \\
\text { SELECT ?subject ?object WHERE \{ } \\
\quad \text { ?subject rdfs:comment ?object. } \\
\text { FILTER(?subject=< } \\
\text { http://pcyti.izt.uam.mx/pmiidas/ } \\
\text { ontomilitar.owl\#Deber_Capitán>)\} }\end{array}$ & $\begin{array}{l}\text { He is } \\
\text { responsible for } \\
\text { the instruction, } \\
\text { good internal } \\
\text { management } \\
\text { and military } \\
\text { spirit of the } \\
\text { force under his } \\
\text { command. }\end{array}$ \\
\hline & $\begin{array}{l}\text { What are the } \\
\text { institutional } \\
\text { values? }\end{array}$ & $\begin{array}{l}\text { SELECT ?subject ?object } \\
\text { WHERE \{ ?subject rdfs:SubClassOf ?object. } \\
\text { FILTER(FILTER(?subject=<http://pcyti.izt.ua } \\
\text { m.mx/pmiidas/ } \\
\text { ontomilitar.owl\#Valor_Institucional>)) }\}\end{array}$ & $\begin{array}{l}\text { Spirit of body, } \\
\text { loyalty, honor, } \\
\text { discipline, } \\
\text { patriotism, } \\
\text { courage, self- } \\
\text { denial and } \\
\text { honesty. }\end{array}$ \\
\hline
\end{tabular}

Domain Expert Evaluation. This evaluation is carried out by experts in the domain, which assess the compliance of the ontology in terms of concepts, hierarchy, standards and requirements [22]. The educational ontology was evaluated by experts in education, specifically in didactics and pedagogy, while the military ontology was evaluated by expert personnel in the military environment (captains and majors). In general, the suggestions of the experts were based on the classification and equivalence of concepts, inclusion of object and data properties; as well as reviewing annotations.

Evaluation through Competency Questions. This test consists of translating the competency questions posed at the beginning of the construction of the ontologies to the SPARQL query language. Table 4 shows the queries made to the educational and military ontology in natural language, the respective queries in SPARQL as well as the result set.

\subsection{Usability Evaluation}

To evaluate the usability of the ontologies, a prototype called MIIDAS was made, which is a web application that makes use of these ontologies and allows users to interact with them by means of a graphical user interface. A usability rubric was used as an evaluation instrument to evaluate ontologies. 
This rubric was applied to 25 professors and 39 students of the Military School of Engineers, all of them are part of the Military Educational System. As an illustration, Figure 2 shows the average of qualification assigned for navigation and utility (the qualification is a number between zero to ten).

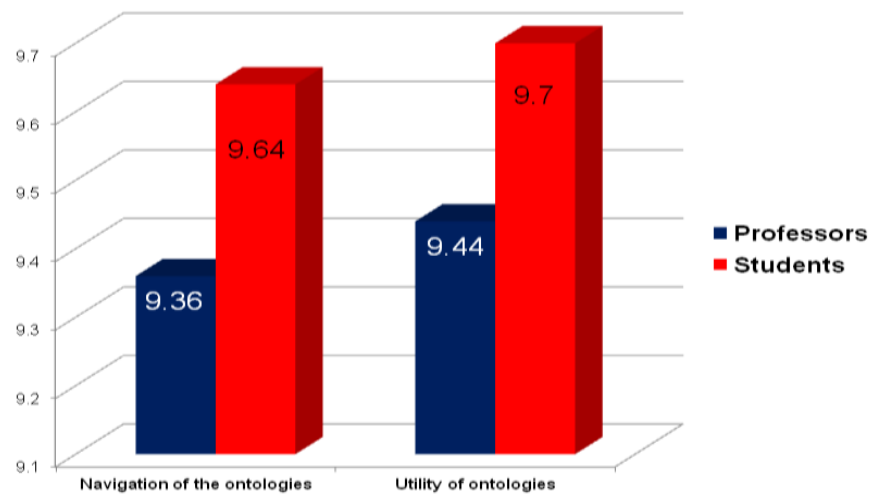

Fig. 2. Average result of navigation and utility for the build ontologies. (Source: own research).

According to the results presented on the evaluation criteria of the ontologies, these were favorable in terms of navigation and usefulness for the student and teaching population, as they reported favorable results for each of these criteria.

\section{Conclusions}

This article describes the process of building two ontologies, one in the educational and the other in the military domains; both ontologies were built by implementing Methodology 101 and considered the context of the Mexican Military Educational System.

Ontologies presented in this work have been preliminary evaluated in three different aspects: structural, functional and usability, obtaining favorable results in each one. These ontologies can serve as a reference to develop multiple applications and as a point of reference to standardize a vocabulary within Mexican institutions.

As future work, we have to research plans, the first is to extend the educational ontology to support training of teacher's evaluation established by the National Institute for the Evaluation of Education (INEE), and the second is to support the impact of the ontology when this is used to support individual's development.

\section{References}

1. Berners-Lee, T., Hendler, H., Lassila, O. The Semantic Web. Scientific American 284(5), pp. 34-43 (2001)

2. Horrocks, I.: Pragmatism and the evolution of semantic systems. In: Pragmatism and the evolution of semantic systems, B. Küppers, U. Hahn and S. Artmann (Ed.), Springer Link, pp. 175-188 (2013) 
3. Labra-Gayo, J.: Web Semántica: Comprendiendo el cambio hacia la Web 3.0. 1st ed. Netbiblo, España (2011)

4. Swoogle Semantic Web Search Engine, http://swoogle.umbc.edu/2006/. Date consulted: 2018/08/10

5. Galindo-Durán, C., Medina-Ramírez, R., Medina-Nieto, M., García-Cué, J.: PMIIDAS: Integration of open educational resources based on semantic technologies. Research in Computing Science 144, pp. 151-165 (2017)

6. Vas, R.: Educational Ontology and Knowledge Testing. The Electronic Journal of Knowledge Management 5 (1), pp. 123-130 (2007)

7. Gahegan, M., Agrawal, R., Banchuen, T., DiBiase, D.: Building rich, semantic descriptions of learning activities to facilitate reuse in digital libraries. International Journal on Digital Libraries 7(1), pp. 81-97 (2007)

8. Curriculum Ontology, https://www.bbc.co.uk/ontologies/curriculum. Date consulted: 2018/10/12

9. Zemmouchi-Ghomari, L., Ghomari, A.: Process of Building Reference Ontology for Higher Education. In: World Congress on Engineering, pp. 1595-1600. London, UK (2013)

10. Smith, B., Kristo, M., William, M.: The Ontology of Command and Control. In: Proceedings of the 14th International Command and Control Research and Technology Symposium (ICCRTS) (2009)

11. Military Ontology Specification-1.1: http://rdf.muninnproject.org/ontologies/military.html. Date consulted: 2018/10/13.

12. Yoo, D., No, S., Ra, M.: A Practical Military Ontology Construction for the Intelligent Army Tactical Command Information System. International Journal of Computers Communications \& Control 9 (1), pp. 93-100 (2014)

13. LeBlanc, E., Nguyen, D., Balduccini, M., Regli, W.: Military Ontologies for Information Dissemination at the Tactical Edge. In: Joint Ontology Workshops, Buenos Aires, Argentina (2015)

14. Gruber, T.R.: A Translation Approach to Portable Ontology Specifications. Knowledge Acquisition 5(2), pp. 199-220 (1993)

15. Gómez-Pérez, A., Manzano-Macho, D. An Overview of Methods and Tools for Ontology Learning from Texts. The Knowledge Engineering Review 19(3), pp. 187-212 (2005)

16. OWL Web Ontology Language Overview, https://www.w3.org/TR/owl-features/. Date consulted: 2018/10/14

17. OWL Web Ontology Language Reference, https://www.w3.org/TR/owl-ref/. Date consulted: 2018/10/14

18. Noy, N.F., McGuinness, D.L.: Ontology development 101: A guide to create your first ontology. Standford Knowledge Systems Laboratory Technical Report KSL-01-05, https://protege.stanford.edu/publications/ontology_development/ontology101.pdf. Date consulted: 2018/09/28

19. OWL: FaCT++, http://owl.man.ac.uk/factplusplus/. Date consulted: 2018/10/16

20. Pellet, http://pellet.owldl.com. Date consulted: 2018/10/16

21. HermiT Reasoner: Home, http://www.hermit-reasoner.com/. Date consulted: 2018/10/16

22. Lozano-Tello, A., Gomez-Perez, A.: Ontometric: A method to choose the appropriate ontology. Journal of Database Management 15(2), IGI-Global Publisher, pp. 1-18 (2004) 